\title{
LA PLANIFICACIÓN EN LOS ESPACIOS NATURALES PROTEGIDOS: APLICACIÓN DE LOS PORN EN LAS CORDILLERAS BÉTICAS ANDALUZAS ${ }^{1}$
}

\author{
Enrique Arias Ibáñez \\ Departamento de Geografía y Ciencias del Territorio \\ Universidad de Córdoba
}

\section{RESUMEN}

El esquema legal que alberga en España los espacios naturales protegidos conlleva la implicación de la Administración regional en las tareas de planificación, ordenación y gestión de los recursos naturales. En Andalucía, al fuerte impulso en su declaración en 1989 no le siguió el mismo interés por aprobar los instrumentos pertinentes, de cuyos retrasos derivaron importantes errores que en los últimos años se están subsanando. En este trabajo se presta especial atención a lo sucedido con la zonificación que los Planes de Ordenación de los Recursos Naturales incorporan como herramienta para la protección y limitación de actividades. Pese a los avances alcanzados, una cuestión clave para la conservación como la regulación de los cambios en los usos del suelo, aún no ha recibido la atención que precisa.

Palabras clave: Parque Natural, planificación, Plan de Ordenación de los Recursos Naturales, zonificación, usos del suelo.

\section{ABSTRACT}

The Spanish legal framework for natural protected areas entails regional government duties on natural resources planning and management. In Andalusia, after the declaring impulse on 1989, there was not the same interest to approve the appropriate instruments; consequence of the delays suffered on them were important mistakes that are being solved in the last few years. In this paper we analyze what has happened with the zoning from Natural Resources Plans as a protection and activities restriction tool. Even after some achieved improvements a key matter for conservation such as land use changes regulation has not received the attention deserved.

Key words: Natural Park, planning, Natural Resources Plan, zoning, land uses.

1 El estudio se inscribe en el marco del Proyecto de Investigación SEJ2004-01129 (Ministerio de Educación y Ciencia), Modificaciones paisajísticas, transformaciones agrarias y nuevos usos y aprovechamientos en espacios naturales protegidos de Andalucía. 


\section{Introducción y objetivos del trabajo}

En una sociedad globalizada en la que abundan planteamientos de desterritorialización y la adopción de modelos de vida cada vez más homogéneos y menos respetuosos con el medio ambiente y las peculiaridades locales, no podemos obviar la relevancia que para el bienestar social tiene la planificación pública.

En este sentido, en la protección de la naturaleza se ha pasado de proteger áreas por su elevado valor como patrimonio natural, paisajístico y sentimental, a intentar reconocer al conjunto del territorio como un todo en el que la naturaleza funciona de forma sistémica constituida por nodos (espacios naturales protegidos) interconectados (corredores ecológicos) en una matriz territorial al amparo de alguna Administración (García et al., 2003). Esto es aún más necesario al considerar como telón de fondo el paisaje mediterráneo, multifuncional por naturaleza, y su ancestral utilización por parte del hombre (VV.AA., 2007). Es en un punto intermedio en el que la Administración ambiental andaluza se encuentra en la actualidad, fomentando el reiterado desarrollo sostenible aunando la protección de una considerable proporción del solar andaluz con medidas a favor del desarrollo socioeconómico de sus poblaciones locales.

De esta forma, sobre gran parte de los espacios protegidos, se han aplicado planes de ordenación y gestión programados en cascada. En nuestro caso, partiendo del estudio de las características esenciales de la protección y planificación ambiental en Andalucía, redundamos en su caracterización en las Cordilleras Béticas utilizando como ejemplo la figura de Parque Natural por su gran representatividad territorial.

Debido a que los primeros planes de ordenación para estos espacios nacieron en 1994 con una vigencia de ocho años, ahora podemos estudiar y evaluar qué cambios se han producido en ellos en su «segunda generación». Sus objetivos y zonificación (realidades a las que debe aspirar la gestión y pilar en el que basar la protección de los recursos naturales respectivamente) se convierten así en punto de atención para conocer mejoras, retrocesos, tendencias, fortalezas y debilidades. Su repercusión estriba en que a partir de ellos se fundamenta la gestión y manejo directo que de los recursos se realiza.

\section{El marco legislativo y la figura de parque natural}

La protección del territorio para salvaguardar sus cualidades ambientales no es una práctica novedosa en las políticas sectoriales, sino que tienen su origen en ideales de conservación de los ecosistemas más valiosos que se remontan a finales del siglo XIX. Estas ideas, cuya primera expresión fue el modelo de Parque Nacional norteamericano (Molina, 1986; Bosque, 1996), se implantan poco después en Europa, aunque pronto fue necesario revisar los planteamientos y principios protectores debido a la secular alteración que la población había ejercido históricamente sobre el territorio.

Es así como desde 1916 se desarrolla en España la historia de la protección del territorio, teniendo hoy una densa trama de espacios protegidos que se distribuye y funciona muy heterogéneamente en función de la región que ocupe. No es momento éste de entrar a analizar las causas del complejo entramado autonómico en lo que a la protección respecta, aunque es obvio que el carácter de legislación básica que la norma estatal tiene ${ }^{2}$, la libertad que otorga al desarrollo competencial autonómico, su desfase temporal con respecto

2 Ley 4/1989, de 27 de Marzo, de Conservación de los Espacios Naturales y de la Flora y Fauna Silvestres. 
al «Estado de las autonomías» y la carencia de unos criterios y normas comunes para el territorio español ${ }^{3}$, han hecho que actualmente no podamos identificar una única política estatal de protección del territorio y sí la superposición de los planteamientos protectores de cada Comunidad (Mulero, 1999 y 2002).

En cualquier caso, para nuestro interés, las aportaciones clave que la nueva Ley tuvo fueron la valoración de los recursos naturales para proteger el territorio, de forma que su conservación y gestión no se produzca sólo en las zonas protegidas; y la inclusión de los Planes de Ordenación de los Recursos Naturales (PORN en adelante) como principal instrumento para dotar a dichos recursos de sus medidas de ordenación y gestión.

Para el caso andaluz nos centramos en la legislación de desarrollo de la Junta de Andalucía ${ }^{4}$ tras la aprobación de la norma estatal. Ésta, no aporta muchas novedades al margen de nuevas figuras protectoras que han tenido escasa repercusión territorial y algunos planes para desarrollar los de ordenación y gestión previstos en la Ley 4/89.

Otro hecho importante a resaltar es el destacado papel que en la política de protección ha adquirido la figura de Parque Natural. Creada al amparo de la Ley de Espacios Naturales Protegidos de 1975 para permitir el contacto entre hombre y naturaleza en áreas con especiales valores naturales, su denominación en la vigente ley estatal se reduce a Parque (art. 13), sin definirla con la tradicional figura de Parque Nacional, símbolo inequívoco de los espacios más emblemáticos. No obstante, la norma andaluza sí que adopta la categoría de Parque Natural, declarando directamente diecisiete sin su previa definición. En cualquier caso, se convierte en la seña de identidad andaluza respecto a la protección del territorio debido a su enorme repercusión superficial y a la identificación de sus planteamientos con la filosofía de sostenibilidad que ansía el aparato legislativo. En efecto, pretender aunar iniciativas de protección, desarrollo socioeconómico y uso público (primordialmente sobre amplias áreas rurales con buen grado de conservación de los recursos naturales), hace que sean ideales como laboratorios territoriales sobre los que practicar políticas que puedan ser aplicables posteriormente a la totalidad de la región, aunque el planteamiento sería más completo si se incardinase en un esquema de planificación territorial a escala regional.

\section{La red de espacios naturales protegidos de Andalucía (RENPA): configuración reciente y significado territorial de las cordilleras béticas}

La red que hoy conocemos es el resultado de la importantísima intervención que la Administración autonómica ha realizado en las dos últimas décadas. El comienzo como tal de esta red data de 1989, ya que aunque anteriormente existieran algunas zonas protegidas -incluso previamente a la constitución de Andalucía como ente administrativo unitario (Zoido, 2002) - , no es hasta entonces cuando se aprueba el marco que hoy regula la declaración y protección del territorio en España y Andalucía.

\subsection{Origen, desarrollo y situación actual de la RENPA}

Tras la aprobación en marzo de 1989 de la ley básica estatal, pocos después y con intención declarativa, vio la luz el texto que desarrolla sus disposiciones en Andalucía. Se crearon 61 espacios que añadir a los 21 previos, con una extensión de casi 1.500 .000

3 Art. 8 de la Ley 4/89: Directrices para la Ordenación de los Recursos Naturales.

4 Ley 2/1989, de 18 de Julio, por la que se aprueba el Inventario de Espacios Naturales Protegidos de Andalucía, y se establecen medidas adicionales para su protección. 
hectáreas (el 17\% de la región) bajo cualquiera de las figuras reconocidas. Sin embargo, este importante paso puede ser objeto de críticas desde distintos puntos de vista.

Tabla 1

LA LEY 4/89: CATEGORÍAS DE PROTECCIÓN Y REPERCUSIONES TERRITORIALES

\begin{tabular}{|c|c|c|c|c|c|c|c|c|c|}
\hline & \multicolumn{2}{|c|}{$\begin{array}{c}\mathrm{N}^{\mathrm{o}} \text { de } \\
\text { espacios }\end{array}$} & \multicolumn{2}{|c|}{ Superficie* } & \multirow{2}{*}{$\begin{array}{l}\% \text { en } \\
1989\end{array}$} & \multicolumn{2}{|c|}{$\begin{array}{c}\text { \% protegido en } \\
\text { Andalucía }\end{array}$} & \multicolumn{2}{|c|}{ \% Andalucía } \\
\hline & 1989 & $T$. & 1989 & $T$. & & 1989 & $T$. & 1989 & $T$. \\
\hline Parq. Nac. & 0 & 1 & 0 & 54252 & 0 & 0 & 3,4 & 0 & 0,6 \\
\hline Parq. Nat. & 17 & 22 & 1077406 & 1443790 & 94,3 & 68,1 & 91,2 & 12,3 & 16,4 \\
\hline Res. Nat. & 14 & 28 & 7747 & 19176 & 0,68 & 0,49 & 1,21 & 0,09 & 0,2 \\
\hline Paraje. Nat. & 30 & 31 & 57417 & 64602 & 5,03 & 3,63 & 4,08 & 0,66 & 0,7 \\
\hline Total (T.) & 61 & 82 & 1142570 & 1581819 & 100 & 72,2 & 100 & 13 & 18 \\
\hline
\end{tabular}

* A lo largo de este trabajo la unidad de superficie que emplearemos será la hectárea.

Fuente: Consejería de Medio Ambiente, 2007. Elaboración propia.

Por un lado, la aplicación de las figuras es muy heterogénea en cuanto a número y extensión superficial, ya que mientras no se hace uso de las categorías de Monumento Natural, Paisaje Protegido, Parque Periurbano y Reserva Natural Concertada, se declaran casi 1.000.000 ha. como Parque Natural junto con más de cuarenta Reservas y Parajes Naturales, si bien estas dos últimas tendrán mucha menos incidencia territorial debido a los requisitos ambientales de los espacios que abarcan y a las presiones de las áreas en las que se ubican (Mulero, 2001 y 2003).

De otro, y aunque este aspecto será ampliado más adelante y no es exclusivo de Andalucía (EUROPARC-España, 2003), es necesario remarcar el daño que le hace a la propia red que la Ley 2/89 nazca con tanta fuerza declarativa, ya que la Administración ambiental se verá desbordada para elaborar los correspondientes PORN que la Ley 4/89 requiere para Parques y Reservas Naturales en el plazo de un año (art. 15).

La consecuencia fue la aparición de un sistema de espacios protegidos que se apoyó primordialmente sobre la categoría de Parque Natural, abarcando más del 91\% del territorio protegido entonces en Andalucía, hecho que se consolida hasta la actualidad aunque se haya avanzado en el desarrollo del resto de figuras.

Desde entonces la declaración de espacios no ha parado de crecer (casi un $11 \%$ desde 1990), si bien es cierto que lo ha hecho de forma más pausada, predominando las áreas de escaso significado territorial. Entendemos pues que se trata de un proceso en el que paulatinamente se va desarrollando la RENPA con los elementos necesarios que le dan coherencia desde un punto de vista formal y, aunque en menor medida, territorial. Esto es, empleando todas las categorías y tratando de consolidar un entramado que abarque los ecosistemas más valiosos en una distribución uniforme sobre el territorio.

De esta forma, a comienzos de 2008 Andalucía cuenta con 150 espacios protegidos (más de 1.700.000 hectáreas), de los cuales 68 se han declarado desde 1990 (cerca de 190.000 ha.), afectando al 19\% del territorio autonómico y a más del $3 \%$ nacional, de cuya superficie protegida en 2005 suponía el 32\% (EUROPARC-España, 2006). 
Tabla 2

LA AMPLIACIÓN DE LA RENPA ENTRE 1990 Y 2005

\begin{tabular}{|c|c|c|c|c|c|c|c|c|c|}
\hline & \multicolumn{2}{|c|}{$\begin{array}{c}N^{o} \text { de } \\
\text { espacios }\end{array}$} & \multicolumn{2}{|c|}{ Superficie* } & \multirow{2}{*}{$\begin{array}{c}\% \text { en } \\
1990- \\
2007\end{array}$} & \multicolumn{2}{|c|}{$\begin{array}{l}\% \text { protegido } \\
\text { Andalucía }\end{array}$} & \multicolumn{2}{|c|}{ \% Andalucía } \\
\hline & $\begin{array}{l}1990- \\
2007\end{array}$ & $T$. & $1990-2007$ & $T$. & & $\begin{array}{l}1990- \\
2007\end{array}$ & $T$. & $\begin{array}{l}1990- \\
2007\end{array}$ & $T$. \\
\hline Parq. Nac. & 1 & 2 & 86208 & 140460 & 45,4 & 4,87 & 7,93 & 0,9 & 1,6 \\
\hline Parq. Nat. & 2 & 24 & 50347 & 1494137 & 26,52 & 2,84 & 84,3 & 0,5 & 17 \\
\hline Res. Nat. & 0 & 28 & 0 & 19176 & 0 & 0 & 1,08 & 0 & 0,2 \\
\hline Mon. Nat. & 37 & 37 & 1046 & 1046 & 0,55 & 0,06 & 0,06 & 0,01 & 0,01 \\
\hline Pai. Prot. & 2 & 2 & 19033 & 19033 & 10,02 & 1,07 & 1,07 & 0,2 & 0,2 \\
\hline Paraje Nat. & 1 & 32 & 26457 & 91059 & 13,93 & 1,49 & 5,14 & 0,3 & 1,04 \\
\hline Parq. Periurb. & 21 & 21 & 5995 & 5995 & 3,16 & 0,34 & 0,34 & 0,07 & 0,07 \\
\hline Res. Nat. Conc. & 4 & 4 & 791 & 791 & 0,42 & 0,04 & 0,04 & 0,01 & 0,01 \\
\hline Total (T.) & 68 & 150 & 189877 & 1685487 & 100 & 10,72 & 100 & 2,1 & 19,2 \\
\hline
\end{tabular}

Fuente: Consejería de Medio Ambiente, 2007. Elaboración propia.

Mapa 1. La Red de Espacios Naturales Protegidos de Andalucía en 2007

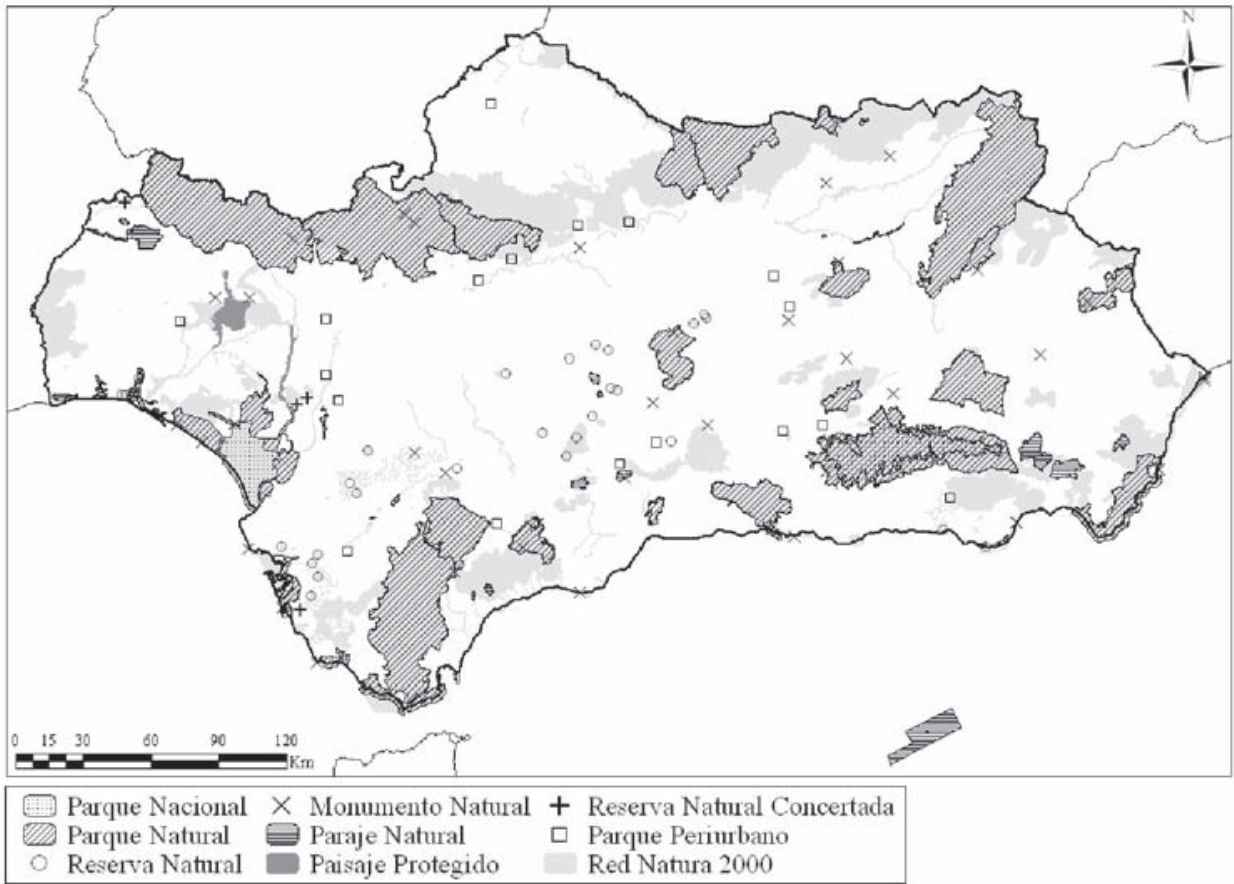

Fuente: Consejería de Medio Ambiente, 2007. Elaboración propia. 
Destaca la creación del Parque Nacional de $S^{\mathbf{a}}$ Nevada y la aplicación del resto de categorías ${ }^{5}$. Este hecho se produce de forma desigual, ya que en un principio se emplean más las propias de la Ley 2/89 — siendo más común la declaración de Parques Periurbanos que de Reservas Naturales Concertadas - para a partir de 2001 comenzar a utilizar las de Monumento Natural y Paisaje Protegido. De entre estas últimas, es más habitual el empleo de la primera, existiendo sólo dos paisajes en la actualidad.

De otro lado, vemos que la aplicación de las figuras más comunes hasta 1989 se ralentiza e incluso se detiene, por lo que podemos hablar de estabilización y homogeneización de la RENPA en conjunto, aunque siempre dentro del predominio territorial de los Parques Naturales $(84,3 \%$ de la superficie protegida).

Por último, no podemos olvidar aquellas áreas que se han delimitado por las iniciativas internacionales de protección de la naturaleza y especialmente de la normativa comunitaria, incorporada a la legislación estatal con la Ley 43/2003 de Montes y contemplada por la norma andaluza como régimen de protección (art. $2^{6}$ ).

En el caso de la normativa comunitaria debemos contemplar las Directivas Aves y Hábitats (79/409/CEE y 92/43/CE respectivamente), cuya representación territorial (ZEPAs y LICs hasta el momento ${ }^{7}$ ) se engloba en la Red Natura 2000. Debido a su solapamiento y a la complejidad que añadiría incluir los datos correspondientes a ambas, los reduciremos a los Lugares de Importancia Comunitaria ${ }^{8}$. En Andalucía, la red, coincidente en un $98 \%$ con los espacios protegidos bajo la normativa nacional y regional, está compuesta por 191 LICs (algo más de 2.500.000 ha., el 29,5\% del territorio autonómico). Baste para comprender su magnitud el hecho de que las 1.391 zonas declaradas en España implican un considerable $22 \%$ del territorio nacional y que las 4.830 de la UE representan el $11 \%$ del comunitario 9 .

Además de la importancia y repercusión territorial que esta iniciativa ha tenido en Andalucía, cabe mencionar la existencia de 20 humedales de importancia internacional (Convenio de Ramsar), nueve Reservas de la Biosfera (Programa Hombre y Biosfera de la UNESCO), un espacio protegido - el Parque Nacional de Doñana- considerado como Patrimonio de la Humanidad (UNESCO), cuatro Zonas Especialmente Protegidas de Importancia para el Mediterráneo (Convenio de Barcelona) y dos Geoparques, formando parte todas ellas de la RENPA ${ }^{10}$ y no sistemas paralelos sin integración.

5 Pese a ello, sigue siendo predominante el territorio calificado bajo cualquiera de las formas de Parque, ya que tan solo tres de estos espacios supondrán más del $70 \%$ del total protegido en dieciséis años.

6 Capítulo II bis de la Ley 4/1989 y art. 2.1 de le Ley 2/89: (...) d) Se entenderá por Zonas de Importancia Comunitaria los espacios naturales protegidos que integran la red ecológica europea «Natura 2000» y que son: Zonas de Especial Protección para las Aves y Zonas Especiales de Conservación.

7 Según el art. 4.4 de la Directiva 92/43/CEE, los LIC deben ser designados por los Estados miembros de la UE como Zonas de Especial Conservación en el transcurso de seis años desde que las correspondientes listas para las regiones biogeográficas hayan sido aprobadas por la Comisión.

8 Por otra parte son además espacios concebidos para una protección más global de los recursos naturales e inspirados en el concepto de «coherencia ecológica».

9 Los LIC andaluces suponen una extensión superior al $21 \%$ de españoles y un $5 \%$ de todos los de la UE.

10 Art. 1 del Decreto 95/2003, de 8 de abril, por el que se regula la RENPA y su Registro: «La RENPA se configura como sistema integrado y unitario de todos los espacios naturales ubicados en el territorio de la Comunidad Autónoma que gocen de un régimen especial de protección en virtud de normativa autonómica, estatal y comunitaria o convenios y normativas internacionales.» 


\subsection{La protección del territorio en las Cordilleras Béticas: caracterización general de los Parques Naturales}

Una vez descrito el contexto general, pasamos a ver brevemente la situación de las Cordilleras Béticas. Contienen 37 áreas protegidas que suponen el $45 \%$ de la superficie catalogada en Andalucía, con un papel fundamental para los Parques Naturales, tanto en la cantidad de espacios como en la superficie implicada en las Béticas (sus más de 800.000 ha. suponen el $86 \%$ aproximadamente) y en el conjunto de la RENPA, en la que los trece significan el $48 \%$ del territorio protegido. Del resto, la mayor parte la ocupa el Parque Nacional de $S^{a}$ Nevada, ya que los veintitrés Parajes y Monumentos Naturales apenas suponen un 3\%. Además, recordamos que aún no se han declarado en esta unidad Paisajes Protegidos, Reservas Naturales o Reservas Naturales Concertadas.

Sin duda, pese a considerarse la más extensa de las unidades geográficas de la región, el empleo de las categorías protectoras es dispar, y es evidente que a su carácter marcadamente montañoso le acompaña un intento de compatibilizar conservación y uso de los recursos naturales, de ahí el empleo predominante de la figura de Parque Natural.

Tabla 3

\section{LOS ESPACIOS PROTEGIDOS DE LAS CORDILLERAS BÉTICAS}

\begin{tabular}{|c|c|c|c|}
\cline { 2 - 4 } \multicolumn{1}{c|}{} & \multirow{2}{*}{$\mathbf{N}^{\mathbf{N}}$} & \multicolumn{2}{c|}{ Superficie } \\
\cline { 3 - 4 } & & Total & $\%$ \\
\hline Parque Nacional & 1 & 86208 & 10,1 \\
\hline Parque Natural & 13 & 824140,7 & 86,6 \\
\hline Paraje Natural & 7 & 27400,5 & 3,2 \\
\hline Monumento Natural & 16 & 436,2 & 0,05 \\
\hline Total & 37 & 765769,5 & 100 \\
\hline
\end{tabular}

Fuente: Corine Land Cover 2000. Elaboración propia.

Este destacado papel territorial de los Parques Naturales y sus propias características como figuras de protección hacen que centremos nuestro trabajo en ellos. Para introducirlos, creemos interesante comentar una serie de datos contenidos en la Tabla 5:

a) La superficie es muy heterogénea, oscilando entre las más de 200.000 ha. del PN S ${ }^{\text {as }}$ de Cazorla, Segura y Las Villas y las menos de 5.000 del PN Montes de Málaga ${ }^{11}$.

b) Se distribuyen, en general, por zonas preferentemente de media montaña; a excepción del Parque Natural Los Alcornocales, todos tienen una altitud media superior a la media andaluza (526 metros) y nueve de ellos por encima de 1.000 metros.

c) Los recursos forestales cumplen un importante papel no sólo en la declaración y protección del espacio, también en su aprovechamiento. Más del $88 \%$ de este territorio está constituido por áreas forestales y casi un $10 \%$ por superficies agrícolas, básicamente ubicadas en el sector Subbético (Moreira, 2003) y la Alpujarra ${ }^{12}$.

11 Su extensión media es de 63.395 ha., muy similar a la de los veinticuatro andaluces (62.641 ha.) y bastante mayor de la superficie media de los espacios protegidos de la región (11.236 ha.).

12 Pese a que predominan las áreas seminaturales, existen grandes variaciones en la superficie relativa dedicada a la agricultura en los Parques Naturales (del 1\% al 37\%; y en seis de ellos por debajo del 5\%). 
Tabla 4

USOS DEL SUELO EN ALGUNOS PARQUES NATURALES DE LAS CORDILLERAS BETICAS

\begin{tabular}{|c|c|c|c|c|}
\cline { 2 - 5 } \multicolumn{1}{c|}{} & $\begin{array}{c}\text { \% sup. construidas } \\
\text { y alteradas }\end{array}$ & $\begin{array}{c}\text { \% sup. zonas } \\
\text { húmedas }\end{array}$ & \% sup. agrícolas & $\begin{array}{c}\text { \% sup. } \\
\text { seminaturales }\end{array}$ \\
\hline Los Alcornocales & 0,14 & 2,57 & 2,42 & 94,87 \\
\hline Sas Subbéticas & 0,36 & 0,00 & 37,93 & 61,72 \\
\hline S $^{\text {a }}$ Mágina & 0,02 & 0,00 & 18,34 & 81,64 \\
\hline
\end{tabular}

Fuente: Corine Land Cover 2000. Elaboración propia.

Mapa 2. Parques Naturales de las Cordilleras Béticas. Usos generales del suelo

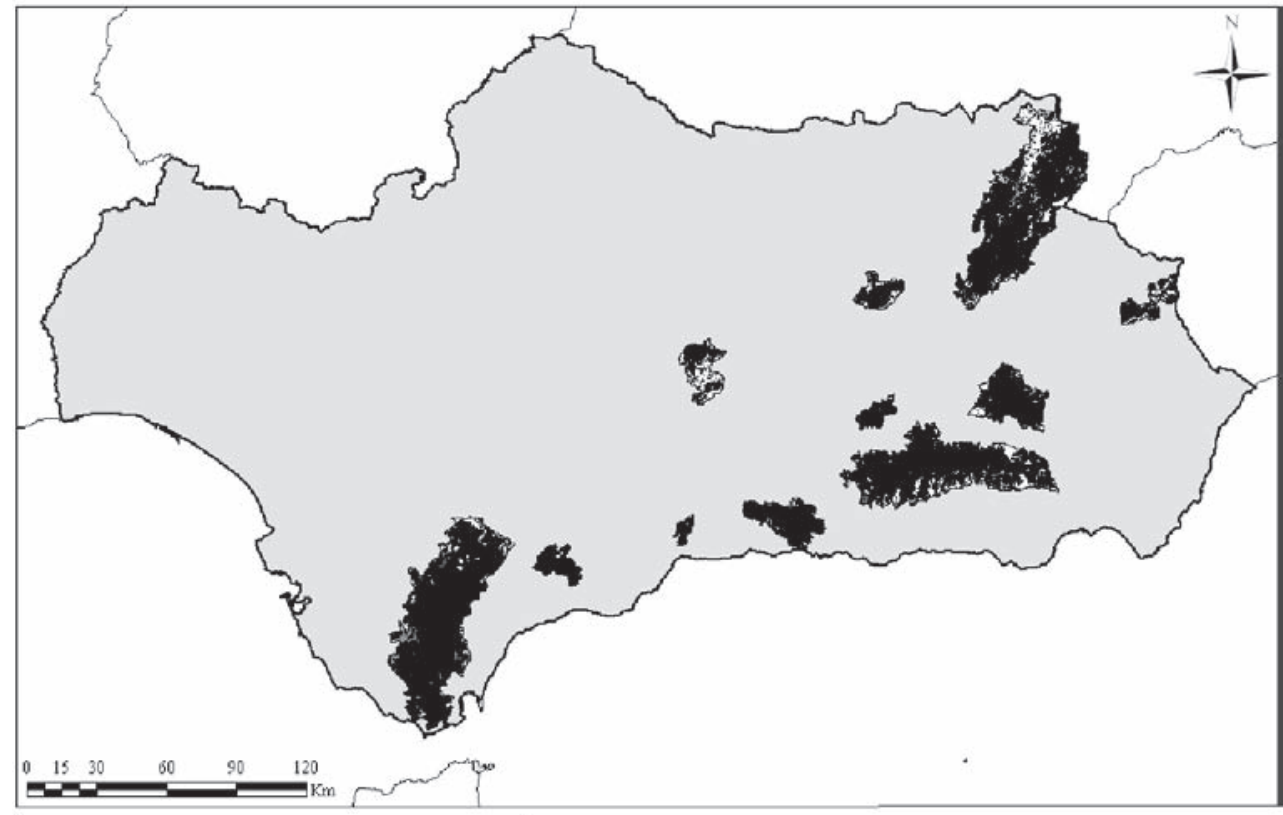

Superficies construidas y alteradas

Zonas húmedas y superficies de agua

Superficies agricolas

Superficies forestales y seminaturales

Fuente: Corine Land Cover 2000. Elaboración propia,

d) En ellos se encuentran 163 términos municipales distribuidos heterogéneamente entre los espacios protegidos, oscilando entre el único que forma parte del PN Sierra de Castril y los sesenta del PN S ${ }^{a}$ Nevada. De aquí se derivan algunas de las dificultades que pueden existir para la gestión de los mismos, a lo que además habría que añadir el estado del planeamiento municipal: sólo 17 de esos municipios están dotados de Plan General aprobado y hasta 25 no tienen ningún tipo de documento urbanístico vigente. 
e) De los datos demográficos extraemos que existe gran variabilidad en la población que albergan los municipios de cada Parque, entre 1.200 y más de 130.000 habitantes, con una media de 47.000. La densidad de población es de 32 hab $/ \mathrm{km}^{2}$, lejos de los 84 del conjunto regional, y con valores que oscilan entre 1 y 65 para el total de municipios de cada espacio. Esta importante y diversa presencia de población indica que se trata de un planteamiento lejos de la protección estricta y totalmente restrictiva con los usos del territorio, pero también que no todas estas áreas pueden ser objeto de un criterio unitario de gestión con respecto a ellos, pues la presión sobre los recursos a priori no es la misma y los intereses de las comunidades locales para su explotación tampoco lo serán.

Todas estas situaciones vienen a confirmar que el modelo de Parque Natural en las Béticas no es homogéneo. Esto se puede concebir como un impedimento en la planificación de la red, así como para su conocimiento y difusión como figura de protección por parte de la población andaluza en general y de la local en particular, hecho clave para involucrar en la consecución de objetivos a los principales actores ${ }^{13}$.

Tabla 5

ALGUNOS DATOS BÁSICOS DE LOS PARQUES NATURALES EN LAS CORDILLERAS BÉTICAS

\begin{tabular}{|c|c|c|c|c|c|c|}
\hline & Sup. & Sup. mun. & Pob.* & $\begin{array}{c}\text { Dens. } \\
\text { pob. } \\
(\text { hab/ } \\
\text { km²)* }^{2}\end{array}$ & Mun. & $\begin{array}{c}\text { Alt. } \\
\text { media }\end{array}$ \\
\hline Los Alcornocales & 167767 & 475857 & 130607 & 27,45 & 17 & 294 \\
\hline$S^{a}$ de Grazalema & 51695 & 139683 & 78366 & 56,10 & 14 & 734 \\
\hline $\mathrm{S}^{\mathrm{a}}$ de las Nieves & 20163 & 95111 & 45395 & 47,73 & 7 & 1014 \\
\hline Montes de Málaga & 4995 & 52966 & 6008 & 11,34 & 3 & 639 \\
\hline $\mathbf{S}^{\text {as }}$ Subbéticas & 32056 & 106164 & 69760 & 65,71 & 8 & 847 \\
\hline$S^{\text {as }}$ de Tejeda, Almijara y Alhama & 40662 & 102893 & 35565 & 34,57 & 12 & 1081 \\
\hline $\mathbf{S}^{\mathbf{a}}$ Mágina & 19961 & 95469 & 34053 & 35,67 & 9 & 1283 \\
\hline $\mathbf{S}^{\mathbf{a}}$ Nevada & 171829 & 322559 & 87244 & 27,05 & 60 & 1736 \\
\hline$S^{a}$ de Huétor & 12128 & 24906 & 11833 & 47,51 & 7 & 1379 \\
\hline $\mathrm{S}^{\mathrm{a}}$ de Castril & 12265 & 24680 & 2614 & 10,59 & 1 & 1527 \\
\hline$S^{\text {as }}$ de Cazorla, Segura y las Villas & 214300 & 364854 & 78711 & 21,57 & 23 & 1215 \\
\hline$S^{a}$ de Baza & 53649 & 112953 & 30637 & 27,12 & 5 & 1546 \\
\hline$S^{a}$ María-Los Vélez & 22670 & 114553 & 1207 & 1,05 & 4 & 1221 \\
\hline Valor medio & 63395 & 156358 & 47077 & 32 & 13 & 1117 \\
\hline
\end{tabular}

* No se han tenido en cuenta los datos poblacionales de Jerez, Algeciras (PN Los Alcornocales) y Málaga (PN Montes de Málaga) por ser ámbitos urbanos de grandes dimensiones — cuyas dinámicas poco tienen que ver con la protección de los recursos naturales-, o por formar parte una pequeña proporción municipal del espacio protegido.

** En metros

Elaboración propia.

13 Algunas preguntas podrían ser: ¿por qué se protege el territorio y se regularizan los usos? ¿para qué sirve cada figura de protección? ¿qué beneficios tiene en el ámbito local, comarcal y/ o regional? 


\section{La planificación en los parques naturales de las cordilleras béticas: evolución y objetivos de los PORN}

Como ya comentamos, la aprobación de la Ley 4/89 supone el inicio de una etapa basada en la planificación de los recursos naturales. Será el PORN el instrumento que guiará una sucesión de documentos orientados a aunar conservación y desarrollo (de Rojas, 2006). Con el transcurso de los años vemos que su aplicación no ha sido lo frecuente y correcta que debiera, sobre todo al inicio, por la magnitud de las redes regionales de espacios protegidos y la falta de interés político por la protección (más allá de las declaraciones) en España ${ }^{14}$ y especialmente en Andalucía.

\subsection{El proceso de aprobación de los PORN}

En primer lugar, podemos hablar de dificultad o imposibilidad administrativa para poder dar soporte a la vasta red de espacios protegidos que se crea con la Ley 2/89, por lo que se apoya en el artículo 15.2 de la norma estatal para posponer la aprobación de los necesarios PORN. Sin embargo, cuando tales planes entraron en vigor, habían pasado cinco años desde su declaración, siendo una mera adopción de modelos territoriales preexistentes, con unos límites preestablecidos y — lo que más daño hace a la propia esencia de lo que se entiende como PORN en la Ley 4/89 — sin ser la declaración fruto de las determinaciones de un análisis y diagnóstico territorial y de los recursos naturales, propios del plan de ordenación (Gómez, 1995; Mulero, 2002).

Se trata de 50 Parques y Reservas Naturales (casi 1.400 .000 ha.) que a partir de 1989 existirán en Andalucía, por lo que resultó material y técnicamente imposible que las instituciones autonómicas fuesen capaces de elaborar los pertinentes PORN para cada espacio, ni tan siquiera progresivamente para ir cumpliendo con los preceptos de la Ley, por la cual deben ser las determinaciones del Plan, a priori, las que dictaminen la necesidad de protección (art. 4.3.d). Así, será el interés por crear una extensa red de protección lo que determine los primeros pasos de la configuración de la RENPA, incluso por encima de las posibilidades y poniendo en riesgo la propia conservación. Esta situación se prolongará hasta 1994, año en el que se aprueban los primeros PORN en Andalucía y, por ende, en las Cordilleras Béticas. Es entonces cuando podemos hablar del comienzo de la planificación «en» la red, aunque no de la planificación «de» la red en sí misma, ya que, como veremos más adelante, no existieron unos mínimos criterios generales comunes ${ }^{15}$ que contemplaran el conjunto de espacios (ni siquiera de Parques Naturales) como una única, aunque diversa intrínsecamente, realidad territorial.

En el siguiente gráfico, presentamos el proceso cronológico de declaración de los Parques y la aprobación de sus PORN en las Cordilleras Béticas: predomina un retraso inicial en la planificación y se observan dos etapas en su evolución, ya que para diez de los doce Parques existentes se aprueban sus respectivos PORN ${ }^{16}$ en $1994 \mathrm{y}$, debido a que nacieron con una vigencia de ocho años, entre 2003 y 2005 vuelven a aprobarse nueve planes de ordenación que suplen a los anteriores, esta vez sí de manera indefinida. Además, en 1999, aparecen dos nuevos planes para sendos Parques Naturales: $S^{\text {as }}$ de Cazorla, Segura y Las Villas, (existente desde 1986) y $\mathrm{S}^{\text {as }}$ de Tejeda, Almijara y Alhama, que es el primer caso

14 Sólo el 26\% de los espacios que requieren PORN lo tienen (Ministerio de Medio Ambiente, 2005).

15 Como tampoco sucede en su caracterización.

16 Lo harán simultáneamente con sus correspondientes PRUG en una dinámica de reiteración y confusión, metodológica y conceptual, de la que no podemos ocuparnos en este momento. 
Gráfico 1. Cronología de los PORN en los Parques Naturales de las Cordilleras Béticas

\begin{tabular}{|c|c|c|c|c|c|c|c|c|c|c|c|c|c|c|}
\hline 2005 & - & & ח & & & $\vdots$ & & & & ! & $\vdots$ & $\vdots$ & $\vdots$ & \\
\hline 2000 & & & & & & & & & & & & & $\vdots \theta$ & $\triangle$ DECLARACIONPN \\
\hline 1995 & & & $=$ & - & - & - & - & - & - & - & - & $=$ & & - 1er. PORN \\
\hline 1990 & & & 0 & 0 & 0 & 50 & 0 & 0 & 0 & 10 & 20 & 0 & : & 口 REVISIÓNPORN \\
\hline 1985 & 0 & & & & & & & & & & & & & \\
\hline & 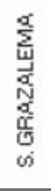 & 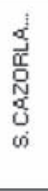 & 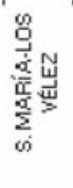 & 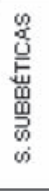 & 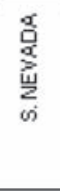 & 总 & $\begin{array}{l}\mathbf{N} \\
\text { a. } \\
\text { w. } \\
\omega\end{array}$ & 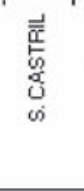 & 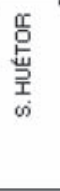 & 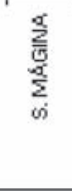 & 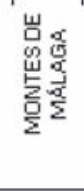 & 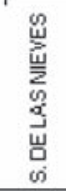 & $\begin{array}{l}\text { 高 } \\
\frac{\alpha}{3} \\
\text { 点 } \\
\text { 岁 } \\
\omega\end{array}$ & \\
\hline
\end{tabular}

Elaboración propia.

en Andalucía de creación de un espacio protegido a partir del PORN, esto es, cumpliendo con los preceptos legales.

Para completar destacamos dos hechos más. El primero es la aprobación en 2006 del PORN para el Parque Natural $S^{\text {a }}$ de Grazalema, declarado en 1984 y sin planificación básica tras la entrada en vigor de las leyes estatal y autonómica. El segundo pasa por la necesidad de aprobar un nuevo PORN para el Parque Natural $S^{a}$ Nevada, ya que el actualmente vigente data de 1994 y fue elaborado con una previsión de ocho años, por lo que está obsoleto, al menos desde una perspectiva legal y administrativa ${ }^{17}$.

\subsection{La evolución de los contenidos y los objetivos en los planes de ordenación}

Del análisis de los instrumentos de ordenación extraemos varias conclusiones:

1. Se constata un cambio radical en la concepción de los planes en su estructura general. Como comentábamos, la similitud entre PORN y PRUG en 1994 es excesiva para tratarse de documentos con definición tan distinta. Esto es especialmente grave en los apartados de zonificación y normativa, en los que se cae en reiteraciones que provocan desorden y confusión, además de las posibles carencias del propio Plan, como la de objetivos. Esto las convierte en herramientas desvirtuadas por su aparición tardía y en instrumentos débiles por su propia concepción (FUNDICOT, 1995). Baste decir que antes de conocer la zonificación aparece la normativa; o que las limitaciones, en lugar de establecerse sobre los usos y actividades, actúan sobre los recursos (Garzón, 2004).

Por contra, los últimos PORN son más coherentes con las determinaciones de la Ley y, ante todo, más ordenados y comprensibles, comenzando con un diagnóstico territorial (que

17 El Decreto 24/2007 declara el Espacio Natural de S ${ }^{a}$ Nevada como ámbito unitario de gestión para el Parque Nacional y Natural, ya que tras las Sentencias del TC 102/1995 y 194/2004 y, consecuentemente, el Real Decreto 702/2006, las competencias de los Parques Nacionales en territorio andaluz se traspasan a la Admón. autonómica. Así, durante 2006 tuvo lugar el periodo de información pública del «Proyecto de Decreto por el que

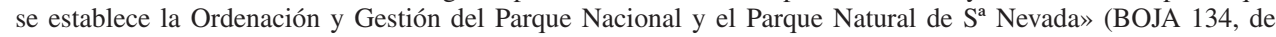
13/07/2006), aunque dichos planes en Enero de 2008 aún no han sido aprobados. 
en el caso anterior aparecía en un apartado previo al plan); continuando con los objetivos en un capítulo entero que los desarrolla; la propuesta de ordenación, que contiene la zonificación; y posteriormente la normativa, general y particular. Respecto a las reiteraciones que en la primera etapa observamos en relación a los planes de gestión, ahora se ha solucionado cumpliendo con una planificación jerárquica, en cascada, desde un planteamiento global del PORN hasta la especificidad en la regulación del PRUG, presentando ambos una estructura general mejor elaborada.

Por su parte, respecto a los dos PORN que se aprobaron en 1999 mencionaremos que el del PN Sas de Cazorla, Segura y Las Villas parece seguir las pautas de 1994, mientras que el de $S^{\text {as }}$ de Tejeda, Almijara y Alhama marca el inicio del modelo que a partir de 2003 seguirán el resto, con ese planteamiento general más coherente al que aludíamos. Tal contradicción evidencia la ausencia de un funcionamiento homogéneo para lo que al menos debería ser una red administrativa (García, 2003).

2. Respecto de los objetivos propios de los planes, sintetizando, hemos de destacar que se observan importantes avances. Se plasman sobre todo en una concepción más amplia del propio espacio protegido y sus peculiaridades, incidiendo en conceptos como el paisaje, la Red Natura 2000, el uso público y los valores culturales, el carácter rural del ámbito, el planeamiento urbanístico, etc., y sobre todo en dos hechos en particular:

- Mayor implicación a la hora de hacer un seguimiento y evaluación del estado de conservación de los recursos naturales, de manera que estos objetivos sean mensurables y se pueda evaluar el grado de implicación y aplicación de las determinaciones del Plan.

- El énfasis en la búsqueda por racionalizar aprovechamientos y conservación, hecho en el que algunos planes inciden implicándose con lo que pretenden sea un «modelo de ordenación coherente y consecuente con la sostenibilidad». Con este modelo territorial se da un paso hacia la consecución de los objetivos de la propia figura de Parque Natural y, por qué no pensarlo, de una red de éstos.

3. La normativa es otro aspecto a considerar por su importancia reguladora. En este caso, aún lejos de implantar un deseable sistema de programación orientado a resultados (EUROPARC-España, 2003), su fundamento en los nuevos planes son las «limitaciones generales y específicas de los usos y actividades» (art. 4.4 de la Ley 4/89) y no sobre los recursos naturales, tal y como se hizo en 1994 (Tabla 6). De esta forma se cumple con las determinaciones legales y se hace un planteamiento más coherente para ordenar dichos recursos y el posterior desarrollo de los instrumentos sobre el espacio protegido.

Tabla 6

NORMATIVA DEL PN SAS SUBBÉTICAS. ALGUNAS DIFERENCIAS ENTRE 1994 Y 2004

\begin{tabular}{|l|l|}
\hline \multicolumn{1}{|c|}{ PORN 1994} & \multicolumn{1}{c|}{ PORN 2004 } \\
\hline III.IV. De la flora y la fauna silvestres & 5.3.2. Activ. y aprovechamientos agrícolas \\
\hline III.V. De los recursos forestales & 5.3.4. Activ. y aprovechamientos forestales \\
\hline III.VII. De los recursos agrícolas & 5.3.8. Infraestructuras viarias \\
\hline
\end{tabular}

Elaboración propia.

Por último, nos gustaría destacar la importancia que para comprender la evolución de la planificación sobre los Parques tiene su zonificación. Es el punto de partida y la clave para la conservación de los recursos y su correcta integración con los aprovechamientos 
tradicionales. En consecuencia, le dedicamos el siguiente epígrafe, al objeto de comprender cuáles han sido sus principales cambios y efectos.

\section{El diseño de la zonificación en los PORN como pilar fundamental de la protección: cambio de criterios y límites}

A nuestro entender, es la zonificación la encargada de delimitar qué espacios dentro del área protegida deben albergar los distintos usos. Es el modelo que guía la protección de los recursos más valiosos, así como el aprovechamiento, en su correspondiente medida y modo, de aquellos otros de interés para la mejora de las condiciones socioeconómicas. Su elaboración entendemos que debe estar ligada al estado de conservación de los recursos naturales y a los aprovechamientos que han permitido secularmente (de Rojas, 2006), por lo que requiere de un análisis y diagnóstico territorial y de la estrecha colaboración entre todas las administraciones y las poblaciones locales. Como indica la Ley 4/89 (art. 4), uno de los contenidos del PORN debe ser la zonificación; supone clasificar el territorio en función de sus cualidades ambientales y socioeconómicas, sus potencialidades y limitaciones, al objeto de reglamentarlas para su protección o compatibilización con determinados usos.

El estudio de la zonificación es especialmente útil en aquellos casos en los que el primer PORN se ha revisado, por lo que el ámbito de las Béticas nos ofrece un amplio abanico de posibilidades. En este trabajo, nos centraremos especialmente en tres tipos de análisis: verificar los cambios que se han producido en el número y nomenclatura de las zonas; comprobar la coincidencia de los objetivos y criterios que las caracterizan; y estudiar cuantitativa y cartográficamente la importancia de cada una. Así, tendremos una visión más clara de las directrices seguidas y de su evolución en estos años.

\subsection{La subdivisión en zonas como primer indicador de la confusión en los PORN}

El origen de la clasificación de un espacio protegido en distintas zonas proviene del Programa Hombre y Biosfera (MAB) y sus Reservas de la Biosfera (Garayo, 1996), para las que se diseña un modelo basado en tres espacios diferenciados por sus peculiaridades ambientales y sus potencialidades de uso: «zona núcleo», «zona tampón»y «zona exterior (de transición)». Años más tarde, este sistema lo adopta de forma generalizada la Administración ambiental andaluza para la zonificación de los Parques Naturales. De momento, nos detendremos en analizar el número, tipo y nombre de cada una de las zonas establecidas en los espacios protegidos que estudiamos.

Como ejemplo, mostramos en la siguiente tabla dos casos significativos que sirven para ilustrar por qué merece la pena destacar este aspecto en la evolución de los PORN.

Resulta fácil comprender cómo se ha pasado de una primera situación de dominante confusión por el número de zonas, sus respectivas subdivisiones y denominación, a otra mucho más sencilla y comprensible, pero es preciso destacar otros dos hechos:

a) En 1994 ni siquiera es homogénea la división en grandes zonas, ya que aunque lo habitual son tres, encontramos casos en los que se hace en dos, cuatro o incluso cinco, como es el caso del PORN del PN de las $\mathrm{S}^{\text {as }}$ de Cazorla, Segura y Las Villas (aprobado en 1999). Éste contrasta notoriamente con el de las $S^{\text {as }}$ de Tejeda, Almijara y Alhama, cuya compartimentación en tres ámbitos y su nomenclatura, muy similar a la utilizada actualmente, hacen difícil creer que ambos planes fueran aprobados el mismo año.

Además, aunque apenas varía su denominación en el conjunto de los Parques, sí que hay un grave defecto en 1994: el empleo siempre de la palabra «protección» en la nomenclatura, cuando ni todo el territorio la recibe por igual, ni se puede hablar estrictamente de ella en 
Tabla 7

EVOLUCIÓN DE LA ZONIFICACIÓN: DIVISIÓN Y NOMENCLATURA DE LAS ZONAS

\begin{tabular}{|c|c|c|c|}
\hline & \multicolumn{2}{|r|}{1994} & 2004 \\
\hline \multirow{7}{*}{$\begin{array}{l}\text { PN Los } \\
\text { Alcornocales }\end{array}$} & \multirow{2}{*}{ Zonas de Prot. A } & Zonas de Protección A.1 & \multirow{2}{*}{ Zonas de Reserva. A } \\
\hline & & Zonas de Protección A.2 & \\
\hline & \multirow{3}{*}{ Zonas de Prot. B } & B-1) Zonas de Protección & \multirow{3}{*}{$\begin{array}{l}\text { Zonas de Regulación } \\
\text { Especial. B }\end{array}$} \\
\hline & & B-2) Zonas de Conservación & \\
\hline & & B-3) Zonas de Regeneración & \\
\hline & \multirow{2}{*}{ Zonas de Prot. C } & $\begin{array}{c}\text { C-1) Zonas de «Producción } \\
\text { Agraria» }\end{array}$ & \multirow{2}{*}{$\begin{array}{l}\text { Zonas de Regulación } \\
\text { Común. C }\end{array}$} \\
\hline & & $\begin{array}{c}\text { C-2) Zonas de regulación de } \\
\text { usos intensivos }\end{array}$ & \\
\hline \multirow{6}{*}{$\begin{array}{l}\text { PN Sierras } \\
\text { Subbéticas }\end{array}$} & Zonas de Prot. A & & A. Zonas de Reserva \\
\hline & \multirow{3}{*}{ Zonas de Prot. B } & Subgrupo I & \multirow{3}{*}{$\begin{array}{l}\text { B. Zonas de } \\
\text { Regulación Especial }\end{array}$} \\
\hline & & Subgrupo II & \\
\hline & & Subgrupo III & \\
\hline & Zonas de Prot. C & & $\begin{array}{c}\text { C. Zonas de } \\
\text { Regulación Común }\end{array}$ \\
\hline & Zonas de Prot. D & & \\
\hline
\end{tabular}

Elaboración propia.

áreas agrícolas, por ejemplo. Ambas situaciones se subsanan en los nuevos documentos, ya que a excepción del PN Montes de Málaga ${ }^{18}$, todos los demás tendrán tres zonas, dirigiendo su denominación hacia una más coherente con los recursos que contienen («reserva», «regulación especial»y «regulación común»).

b) Las subdivisiones de las grandes unidades es un caso aún más complejo. En 1994 se establecen habitualmente para cada zona, siendo especialmente abundantes en algunos casos concretos ( $S^{\text {a }}$ Nevada tiene ocho diferenciaciones para su sector $\left.A\right)$ y, en general, para las del «Grado B». Su origen es dispar entre los propios Parques y dentro de cada área protegida. Se emplean denominaciones según la restricción («protección», «conservación»...), los usos, la cubierta vegetal, el estado de conservación o incluso divisiones numéricas. Sin duda se trata de un claro síntoma de descoordinación a la hora de elaborar un patrón de gestión, uso y entendimiento común en todos los Parques. Por contra, desde 2003 la situación se homogeneiza, ya que a una drástica reducción de los casos con subdivisiones y a su menor número cuando se recurre a ellas, se unen unos criterios de delimitación no tan dispersos. A pesar de ello, es un aspecto en el que se podría haber avanzado más. Así, con el transcurso de los años se ha corregido la caótica situación inicial de la nomenclatura empleada en la zonificación de los PORN de 1994.

18 El hecho de estar dividido en dos zonas se debe más a su origen como área de esparcimiento para la población de la capital malagueña que al valor ecológico de sus recursos naturales. 


\subsection{Cambios en los objetivos y criterios de la zonificación}

Entendemos que un correcto ejercicio de ordenación para un conjunto de espacios protegidos catalogados bajo la misma categoría, consiste en aplicar unas pautas generales para determinar qué tipo de características debe tener una zona para incluirla en alguno de los grupos, sin olvidar las peculiaridades de cada territorio.

Aclaramos que los objetivos y criterios que vamos a tratar son los correspondientes a las grandes zonas de división del Parque Natural, ya que profundizar en las subdivisiones induciría a confusión debido a su elevado número y heterogéneo origen.

- Zonas A. Hemos detectado una renovación en la idea de reserva, puesto que se evoluciona a un planteamiento más amplio del estrictamente conservacionista expuesto en 1994. Ahora, además de los ecosistemas de alto valor ambiental, se incluyen aquellos que puedan alcanzarlo — siendo posible una explotación subordinada a la protección en sí-, de forma que no se trate de «islotes de naturaleza» al margen de la dinámica del Parque (Castro, 2002). También se amplía su definición, incluyéndose otros factores que en los primeros planes no se preveían, como características geomorfológicas o criterios paisajísticos, avanzándose pues desde puntos de vista eminentemente botánicos o faunísticos, a otros más completos que consideran los recursos naturales en conjunto.

Por último, destacaremos la evolución hacia la coherencia que los objetivos adoptan con respecto a la definición de las zonas y su concreción, ya que sin ser exhaustivos ni entrar en pormenores (innecesarios para un PORN), sí que superan el grado de indefinición de los planes de 1994, cubriendo mejor las necesidades de cada sector.

- Zonas B. Se tiende igualmente a la homogeneización de criterios y objetivos en su definición, aunque en este caso la diversidad de planteamientos de 1994 era más fruto de la multiplicidad de subzonas creadas que de la propia concepción de este espacio como amplias áreas para el desarrollo sostenible. Es por ello por lo que además de ser la zona más extensa en los Parques Naturales, podemos identificarla con la propia esencia de esta categoría de protección. Caracterizadas por su buen estado de conservación y por compatibilizar usos y valores naturales, la dinámica general muestra la eliminación de las actividades agrícolas y una caracterización más completa y pormenorizada.

- Zonas C. Se contemplan en todo momento como las de menor valor naturalístico, aunque tengan que ser integradas paisajísticamente en el conjunto del Parque, deban considerarse ambientalmente o, ahondando en su concepción teórica, necesiten estar definidas correctamente. Pero esta definición no existía en 1994, encontrándonos con dos situaciones: la primera de ellas, de poco sustento técnico, las clasificaba por ausencia de elementos naturales de interés; la segunda, basada en los usos del suelo, incluía los espacios más antropizados, aunque sin concretarlos. Sin embargo, para los planes aprobados desde 2003, la conceptualización es más nítida, lo que se plasmará en su repercusión espacial. Dentro de la delimitación de actividades que formarán parte de ellas destaca la presencia de las áreas agrícolas (cuyo papel se reducirá en las áreas de regulación especial o B), además de aquellas de carácter intensivo sobre el territorio.

La definición de objetivos también mejora. Teniendo en cuenta la compatibilización de los usos con la conservación, el paisaje, el fomento de la biodiversidad, el uso público, etc., parece que el planteamiento no es simplista como en 1994 («cumplir con los objetivos generales del Parque»), avanzándose hacia objetivos propios. 


\subsection{Análisis cuantitativo y cartográfico de la zonificación}

El estudio realizado lo completamos con una valoración gráfica y estadística de los cambios acontecidos en la zonificación entre los PORN de 1994 y los aprobados desde 2003. De esta forma los resultados son objetivos y contemplamos, mediante el empleo de un sistema de información geográfica, la posibilidad de relacionar la ordenación del Parque con otro tipo de datos (usos del suelo, relieve, etc.). Para ello hemos escaneado, digitalizado y georreferenciado la cartografía de ordenación contenida en los planes. De ello se deriva la posibilidad de que existan errores en los cálculos que a continuación presentamos, aunque su cuantía podemos considerarla despreciable teniendo en cuenta que las magnitudes superficiales con las que trabajamos superan los miles de hectáreas y que no es precisamente la escala de detalle la que predomina en un PORN.

De este modo presentamos los resultados de comparar los distintos instrumentos de ordenación centrándonos especialmente en: la visualización de los cambios en la zonificación de los espacios que disponen de un segundo PORN; la relación que ésta guarda con los usos del suelo - datos del Proyecto Corine Land Cover (Consejería de Medio Ambiente, 2004) — y sus cambios entre 1991 y 1999; y los vínculos entre las áreas de reserva y las de mayor altitud en los Parques, como posible interpretación de la muy difundida idea de aquéllas como las más inaccesibles y mejor conservadas.

\subsubsection{La repercusión territorial de los cambios acontecidos con la nueva zonificación}

Un primer análisis de lo que ha supuesto la revisión de nueve PORN en las Cordilleras Béticas ${ }^{19}$ nos muestra que, en general, se ha enfatizado la protección sobre las áreas protegidas. Los datos obtenidos de calcular la superficie ocupada por cada tipo de zona son clarificadores (Tabla 8), mostrando un destacado crecimiento de las áreas de regulación especial junto a otro más suave de los espacios de reserva, hechos que se producen sobre el retroceso de aquellos de regulación común, reducidos a la mitad.

Tabla 8

CAMBIOS EN LA IMPORTANCIA RELATIVA DE CADA ÁREA EN LA ZONIFICACIÓN

\begin{tabular}{|c|c|c|}
\cline { 2 - 3 } \multicolumn{1}{c|}{} & \% PORN 1994 & \% PORN 2003 \\
\hline Zonas de reserva (A) & 7,77 & 9,44 \\
\hline Zonas de regulación especial (B) & 73,06 & 81,12 \\
\hline Zonas de regulación común $(\mathbf{C})$ & 19,17 & 9,44 \\
\hline
\end{tabular}

Elaboración propia.

Sin embargo, debemos matizar que aunque crecen en general las zonas A, la importancia relativa que tienen respecto a las B es muy débil, pues apenas son $10 \%$ del territorio protegido. Estas últimas representan porcentajes abrumadoramente mayoritarios que afianzan la vocación de este nivel protector como aquél en el que se combinan la conservación

19 Los Parques Naturales $S^{a}$ María- Los Vélez, Sas Subbéticas, S ${ }^{a}$ Mágina, S Huétor, S Castril, S $S^{\text {a }}$ Baza, Los Alcornocales, $S^{a}$ de las Nieves y Montes de Málaga tienen PORN de 1994 y 2003. S ${ }^{a}$ Nevada sigue con el Plan de 1994; Sas de Cazorla y Sas de Tejeda con el de 1999; y Sa de Grazalema lo aprobó en 2006. 
y el desarrollo socioeconómico (Arenas, 1998). Por tanto podemos hablar de un mayor interés proteccionista que se apoyará, entre otras cosas, en una consideración mucho más racional y estricta de los espacios que deben ocupar las áreas de menor valor ambiental del territorio protegido, cuya delimitación debe circunscribirse a las zonas más afectadas por las actividades humanas.

Otro análisis numérico viene a constatar esta afirmación, y es que de las más de 62.000 ha. en las que se han producido cambios de zonificación ${ }^{20}$, más de 49.000 (el 78,7\%) experimentan un incremento de la protección: tres cuartas partes son cambios de zonas $\mathrm{C}$ a B; un $20 \%$ pasa de áreas de regulación especial a las de reserva; y alrededor de un 5\% cambian de regulación común al máximo nivel. Por otra parte, apenas unas 13.000 ha. han disminuido su protección: el 52\% presenta cambios de áreas de reserva a las de regulación especial y el $47,5 \%$ de éstas a las de regulación común, mientras que apenas se producen cambios significativos (47 ha., el 0,35\%) entre zonas A y C.

\subsubsection{La zonificación y su relación con los usos del suelo}

Un aspecto que creemos esencial para ordenar y planificar un espacio protegido es el de sus aprovechamientos del suelo. Su valor es tan destacado porque forma parte de la dinámica misma del territorio; es la auténtica muestra de las actividades que en él acontecen y, por tanto, del posible deterioro o estado de conservación de los recursos y el paisaje. Es además un indicador fiable y de utilidad si empleamos series con datos de usos del suelo obtenidas de manera homogénea en distintos momentos históricos.

En esta línea, hemos empleado la información de usos y coberturas vegetales del suelo de Andalucía para 1991 y 1999, años previos a la aprobación de los PORN de 1994 y de los más recientes. Así analizamos qué clase de ámbitos han sido los prioritarios para cada tipo de zona, su evolución y si ésta ha sido determinante en los cambios de la zonificación. Con el objeto de simplificar la clasificación de esta cartografía y hacer un estudio sobre el valor que hayan podido tener los cambios en la conservación, dividimos la información en nueve valores correlativos en función de sus cualidades ambientales, de menor a mayor. De la diferencia de ambos valores entre 1991 y 1999 deducimos la tendencia (positiva o negativa) del territorio en cuestión.

De la distribución de los usos en cada tipo de zona podemos llegar a varias conclusiones: (1) existe un claro predominio de las áreas de matorral y boscosas en las zonas de reserva de los planes de 1994 y en los más recientes, teniendo el resto de superficies una repercusión insignificante. (2) Para las áreas B cabe destacar que, en esencia, son las mismas superficies nombradas anteriormente las predominantes. Eso sí, en este caso las áreas de pastizal aumentan adquiriendo un papel ya significativo. (3) De la evolución de ambas zonas deducimos que, aunque sea positiva la disminución de espacios agrícolas y sin vegetación, es preocupante que incrementen las superficies construidas, especialmente en las zonas de reserva, pasando de su inexistencia a unas 60 ha. en la nueva zonificación. (4) La gran diferencia estriba, como apuntábamos, en los cambios que se producen en la concepción de los espacios de regulación común (zonas C). El hecho es tal que aunque las superficies agrícolas y alteradas apenas cambian en datos absolutos, sí que pasan a ser mayoritarias en estos sectores con los nuevos PORN. Su fundamento es que el territorio ocupado en ellas por las superficies naturales se reduce drásticamente, estando ahora fundamentalmente incluido en las zonas A y B.

20 El 8\% del área protegida en estos nueve PORN cambia su nivel protector entre 1994 y la actualidad. 
Se trata de una adaptación de los criterios que rigen cada zona, siendo en la actualidad más racionales, coherentes y homogéneos que en los primeros planes. Tal vez aquellos fueron erróneos y precipitados por la propia celeridad con la que tuvieron que aprobarse los PORN para dotar de un cuerpo planificador a los Parques Naturales de 1989 (a pesar de los inconcebibles retrasos administrativos y los cinco años que se emplearon para su aprobación). Sin embargo, lo que no podemos aseverar es que exista una relación contundente y objetiva entre la evolución que han seguido la zonificación y la dinámica de los usos y aprovechamientos, ya que a los cambios en éstos no le suceden adaptaciones de aquella, así como la propia delimitación de distintas tipologías de áreas en el espacio protegido no ha implicado una notoria mejoría ambiental.

Para comprenderlo resulta de gran utilidad la cartografía elaborada al respecto, de la que presentamos un ejemplo (Mapa 3). En él apreciamos cómo un mayoritario incremento de las zonas A y B no se corresponde con una evolución positiva —en términos ambientales- de los usos del suelo (ni en proporción ni ubicación); incluso se detectan fenómenos de deterioro ambiental en sectores que aumentan su protección.

Mapa 3. Evolución de la zonificación y los usos del suelo en el PN Sierra de Castril

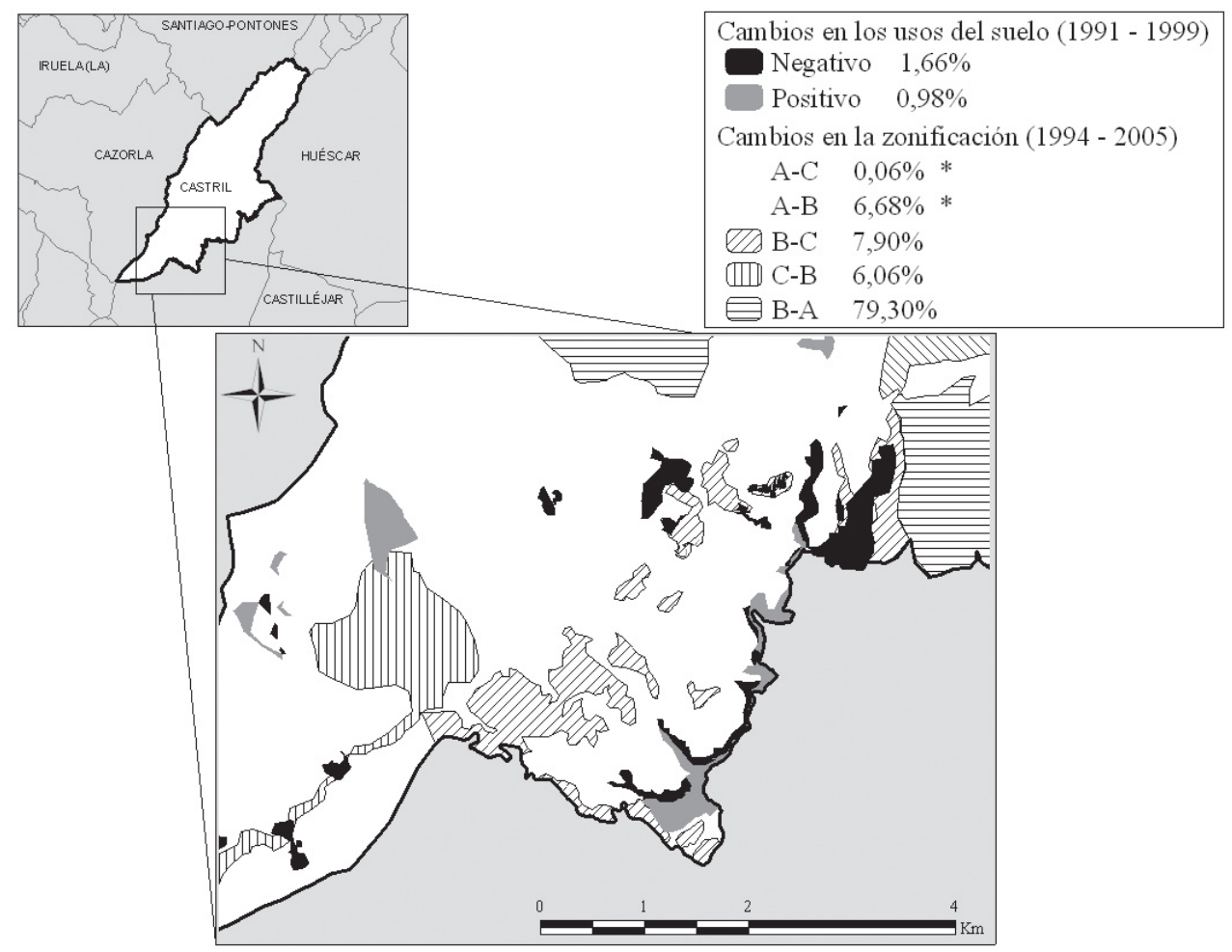

* Dichos cambios en la zonificación no están presentes en el área seleccionada.

Fuente: Corine Land Cover 2000. Elaboración propia. 
Tabla 9

TIPOS DE USOS Y LA EVOLUCIÓN DE LA ORDENACIÓN EN LOS PN DE LAS BÉTICAS

\begin{tabular}{|c|c|c|c|c|c|c|}
\hline & \multicolumn{2}{|c|}{ ZONA A } & \multicolumn{2}{|c|}{ ZONA B } & \multicolumn{2}{|c|}{ ZONA C } \\
\hline & $\begin{array}{c}\% \\
1994\end{array}$ & $\begin{array}{c}\% \\
2003\end{array}$ & $\begin{array}{c}\% \\
1994\end{array}$ & $\begin{array}{c}\% \\
2003\end{array}$ & $\begin{array}{c}\% \\
1994\end{array}$ & $\% 2003$ \\
\hline 0. Sup. construidas y alteradas & 0 & 0,1 & 0,1 & 0,1 & 0,4 & 0,5 \\
\hline $\begin{array}{l}\text { 1. Sup. agrícolas y abiertas. Poca o sin } \\
\text { vegetación }\end{array}$ & 3,5 & 1,2 & 4,1 & 2 & 36,9 & 68,6 \\
\hline $\begin{array}{l}\text { 2. Sup. agrícolas con vegetación natural. } \\
\text { Talas y repoblaciones recientes }\end{array}$ & 1,2 & 1,5 & 1,9 & 0,7 & 1,8 & 3,6 \\
\hline 3. Sup. naturales. Pastizal sin arbolado & 0,7 & 3,2 & 3,7 & 4,6 & 14 & 10,3 \\
\hline 4. Sup. naturales. Matorral sin arbolado & 24,1 & 27,2 & 19,4 & 20,9 & 17 & 5,8 \\
\hline 5. Sup. naturales. Pastizal con arbolado & 0,9 & 0,9 & 3,3 & 4 & 5 & 3,3 \\
\hline $\begin{array}{l}\text { 6. Sup. naturales. Matorral disperso con } \\
\text { arbolado }\end{array}$ & 36,8 & 34,9 & 24,2 & 26,1 & 16,4 & 4,7 \\
\hline $\begin{array}{l}\text { 7. Sup. naturales. Matorral denso con } \\
\text { arbolado }\end{array}$ & 6,2 & 5,8 & 17,3 & 16,2 & 5 & 1,1 \\
\hline $\begin{array}{l}\text { 8. Sup. naturales. Arboladas densas y zonas } \\
\text { húmedas }\end{array}$ & 26,1 & 24,8 & 25,6 & 25 & 3,1 & 1,7 \\
\hline
\end{tabular}

Fuente: Corine Land Cover 2000. Elaboración propia.

En general para el conjunto de espacios protegidos, mientras que 62.000 ha. cambian el tipo de zona a la que pertenecen, 31.000 lo hacen en sus usos, sin que se produzcan coincidencias nítidas entre ambas capas de información. A su vez, al tiempo que el 78\% de las modificaciones en la zonificación se corresponden con un incremento de la protección, sólo el 58\% de los cambios en los aprovechamientos se producen en aras de un mejor estado de conservación de los recursos. Esto además se puede matizar, pues en las áreas de reserva y comunes los cambios en los usos son principalmente de carácter negativo, esto es, con mayor pérdida que mejora de su valor ambiental.

\subsubsection{La relación entre las áreas de reserva y la altitud}

Sin duda, el aspecto esencial a considerar para incluir una porción del territorio en el área de reserva es su estado de conservación. Para ello, entendemos que existen multitud de factores, por lo que considerarlos es imprescindible para la ordenación del área protegida y sus zonas más valiosas. En este caso partimos de la concepción de las zonas más elevadas de los Parques Naturales (de orografía montañosa en las Béticas como ya señalamos anteriormente) como aquéllas con baja accesibilidad y buen estado de conservación ${ }^{21}$. No

21 Debemos incidir en este plano teórico, ya que existen multitud de factores que afectan en esta decisión y nosotros, a modo orientativo, consideramos sólo la altitud, independientemente del estado de conservación de la vegetación, la fauna, posibles endemismos, estudios de paisaje, accesibilidad, etc. 
obstante, no podemos generalizar, pues ni el ascenso en altitud implica aislamiento o un estado favorable de conservación, ni todos los espacios con los que trabajamos presentan elevaciones montañosas de relevancia más allá del papel relativo que cumplen en su ámbito, de modo que el uso de sus recursos puede hacerse sin condiciones (climáticas, geomorfologías, edafológicas...) realmente excluyentes.

Partiendo de la concepciónque algunos PORN hacen de sus áreas de reserva a partir de alguna curva de nivel, calculamos el área que para cada Parque ocupa su zona de reserva. El resultado lo extrapolamos a un modelo digital de elevaciones tomando los píxeles que, en conjunto, ocupan tal superficie, partiendo de la mayor altitud y disminuyendoprogresivamente hacia los más bajos hasta obtener la misma superficie que el área de reserva posee. El resultado son los sectores más elevados que, agrupados, representan la misma superficie que las zonas A. Esta operación, repetida en cada espacio para cada uno de sus planes, nos permite comprobar si la altitud ha sido considerada para delimitar las áreas de mayor protección, así como su evolución ${ }^{22}$.

A continuación (tabla 10 y mapa 4) se presentan algunos de los datos logrados, de los cuales se deduce que, aunque la altitud es un factor importante en el grado de protección, no es único y determinante ${ }^{23}$. Además, comprobamos que tampoco es homogénea la evolución de los planes en esta relación, aunque sí existe una tendencia general de su incremento si sumamos los valores evolutivos de cada Parque Natural.

Tabla 10

RELACIÓN ENTRE LAS ZONAS A Y LAS ÁREAS MÁS ELEVADAS DE LOS PARQUES NATURALES

\begin{tabular}{|c|c|c|c|c|c|c|c|}
\hline & \multirow{2}{*}{$\begin{array}{c}\text { Sup. A } \\
1994\end{array}$} & \multirow{2}{*}{$\begin{array}{c}\text { Sup. A } \\
2003\end{array}$} & \multicolumn{5}{|c|}{ Sup. de las zonas A en áreas de cumbres } \\
\hline & & & 1994 & $\%$ & 2003-2005 & $\%$ & Evolución \\
\hline Sas Subbéticas & 1327 & 3873 & 819 & 61,7 & 1376 & 35,5 & $-26,2$ \\
\hline$S^{a}$ de Castril & 689 & 3058 & 56 & 8,1 & 783 & 25,6 & 17,4 \\
\hline $\mathrm{S}^{\mathbf{a}}$ de las Nieves & 5297 & 4964 & 1975 & 37,3 & 2606 & 52,5 & 15,2 \\
\hline$S^{a}$ de Huétor & 528 & 382 & 24 & 4,5 & 6 & 1,6 & $-2,8$ \\
\hline $\mathrm{S}^{\mathbf{a}}$ Mágina & 1934 & 1793 & 1095 & 56,6 & 1351 & 75,3 & 18,7 \\
\hline $\mathrm{S}^{\mathbf{a}}$ Nevada & 25472 & - & 22899 & 89,9 & - & - & - \\
\hline
\end{tabular}

Elaboración propia.

22 No se incluye el PN Montes de Málaga por no haber delimitado en sus PORN áreas de reserva.

23 A excepción del caso concreto del PN Sa Nevada, justificado por el indudable valor ambiental y la excepcional altitud de sus cumbres en unas latitudes tan meridionales como las andaluzas. 
Mapa 4. Evolución de la zonificación en el Parque Natural Sierra de las Nieves

1994

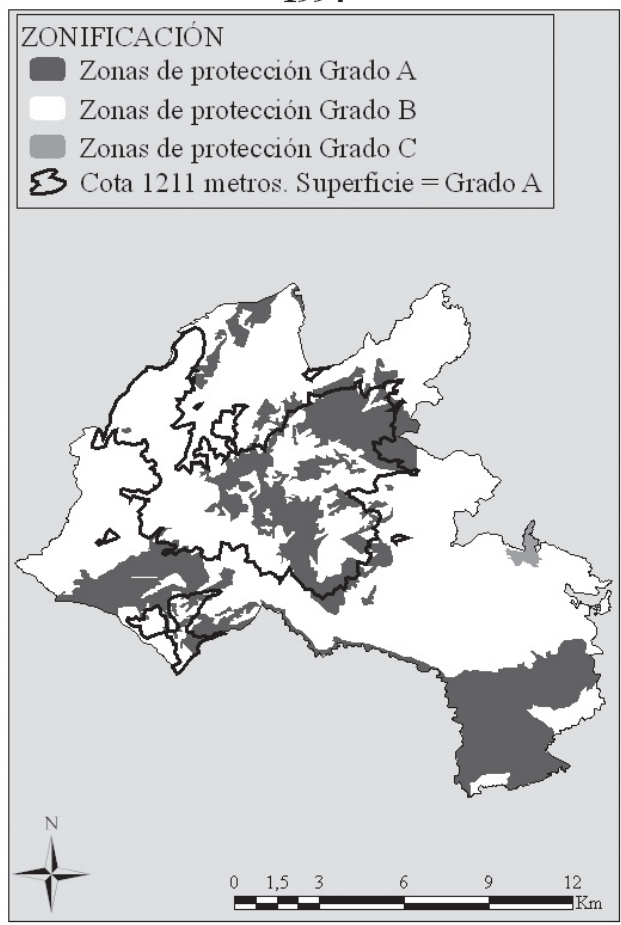

2003

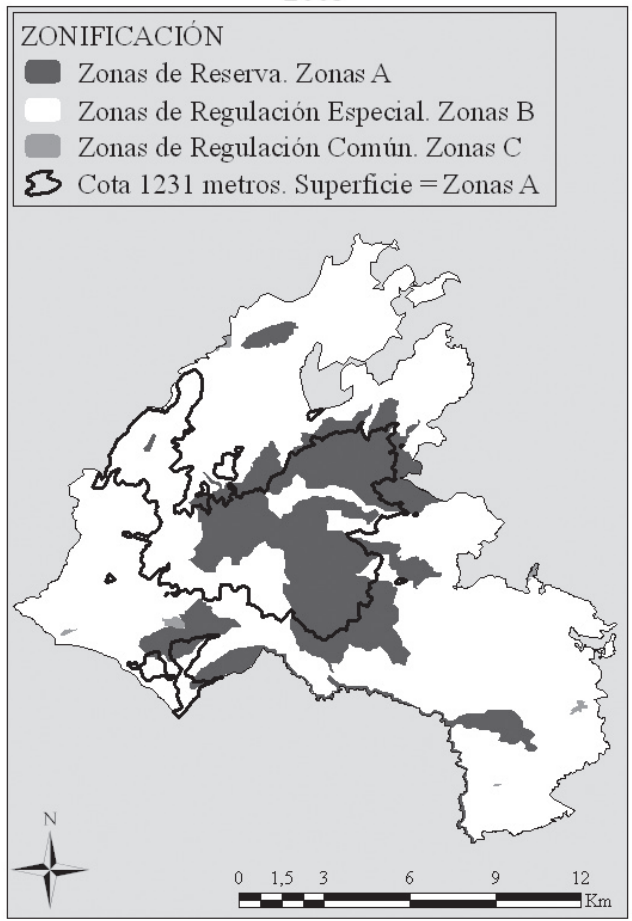

Elaboración propia.

\section{Conclusiones}

1.- Como se ha tenido oportunidad de ver a lo largo de este trabajo, existen diversas situaciones que impulsan a afirmar que no podemos hablar estrictamente de una red de Parques Naturales en Andalucía. De entre ellas destaca la poca homogeneidad de criterios a la hora de seleccionar los territorios que formarían parte de dicha categoría protectorasuperficie total, tipología de usos y aprovechamientos, número de municipios y densidad de población, principales objetivos a cumplir, etc. —al margen de tratarse de espacios de montaña en los que habitualmente existen problemas de aislamiento económico y déficit de infraestructuras acompañados de un aceptable estado de conservación de los recursos naturales (Mulero, 2003)—. Además, esta variada casuística enlaza con una débil tradición de planificación, territorial y ambiental, en España (Cruz, 1999; EUROPARC-España, 2005), la ausencia de planteamientos de escala regional para la gestión del territorio (Arenas, 1998) y el, a nuestro entender, error inicial de mostrar mayor interés por la declaración de una extraordinariamente extensa red de espacios protegidos que por su verdadera ordenación y gestión. Su consecuencia ha sido una multiplicidad de puntos de vista en los objetivos, criterios y zonificación de cada Parque Natural. 
2.- Lo anterior se ha constatado en un lento proceso de aprobación en los correspondientes PORN de los espacios protegidos que aún no ha finalizado, pues todavía debe renovarse el Plan de Sierra Nevada. Su origen reside en las desproporcionadas dimensiones de la red que se creó en 1989, que ocasionó serios problemas para su gestión administrativa y la efectividad de sus determinaciones sobre el territorio, dificultades que hoy persisten.

3.- Con este panorama general, gracias al estudio de los primeros PORN y su revisión, analizamos pormenorizadamente los cambios en la zonificación de cada Parque Natural de las Béticas, mostrando un especial interés por sus objetivos y la plasmación territorial de sus diferentes zonas. De ello extraemos lo siguiente:

a) Una mejora expositiva y de contenidos que se produce desde 1999 a raíz del PORN del PN Sierras de Tejeda, Almijara y Alhama (primer caso en la RENPA en el que se declara un espacio protegido por efecto de la planificación), afianzada en la revisión hecha en los planes a partir de 2003. Esto es, una estructura más coherente y organizada del propio documento y en la distribución de sus contenidos con respecto a sí mismo y al PRUG. Un ejemplo es la simplificación y homogeneización en la nomenclatura y criterios de delimitación de los tres (como generalización) tipos de zonas en los que se divide el Parque Natural, así como la casi total eliminación de sus subdivisiones, fruto en los noventa de una gran confusión conceptual y terminológica.

Mapa 5. Evolución de la zonificación en el Parque Natural Montes de Málaga
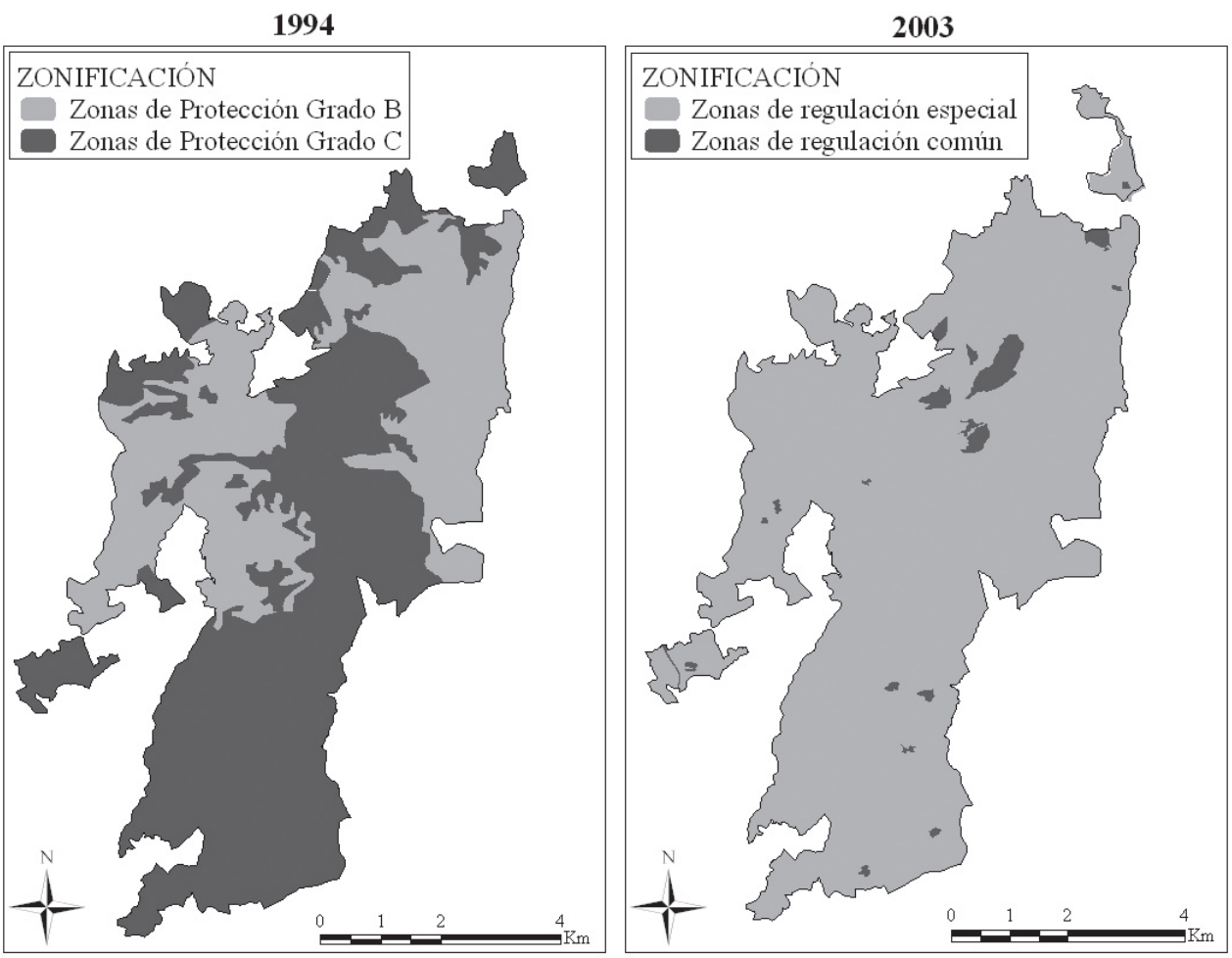

Elaboración propia. 
b) En segundo término podemos hablar de una clara tendencia proteccionista, fundada en el incremento de las superficies destinadas especialmente a la conservación y protección (zonas A y B), en detrimento de aquellas que gozan de mayor permisividad de usos. Esto se produce fundamentalmente por una mejora en los criterios para delimitar los tipos de superficie que quedan afectados por las zonas de regulación común, restringidas ahora a las áreas agrícolas, construidas y alteradas. En este proteccionismo, sin duda la representatividad la ostentan las áreas de regulación especial (B), auténtico exponente de la filosofía que impregna la RENPA, aunando iniciativas de conservación, desarrollo socioeconómico y uso público.

c) Sin embargo, esta dinámica general positiva no debe hacernos olvidar otros aspectos importantes como la evolución de las zonificaciones. En su consideración establecemos tres grupos de Parques Naturales: en el primero hay estabilidad y homogeneidad entre ambos planes; el segundo agrupa los casos en que existe un claro aumento del proteccionismo (Mapa 5); y el tercero reúne aquellos Parques cuya zonificación ha experimentado cambios asociados a una reinterpretación de las zonas A y B, sin apenas alteraciones en la concepción y delimitación de las C (Mapa 4).

Estas modificaciones podrían tener una doble interpretación: de un lado, cuestionar la eficacia de la gestión desarrollada los primeros años al cambiar drásticamente la normativa (algo que sin duda será beneficioso, y no sencillo, si se trata de conservar zonas de buen valor ambiental); de otro, suponer una reorientación de la ordenación hacia criterios comunes que corrijan la precipitación de los primeros pasos dubitativos en la planificación ambiental andaluza.

En cualquier caso, no hemos hallado correlación alguna entre cambios de usos del suelo y las nuevas zonificaciones establecidas.

d) Se produce un afianzamiento de la tipología de usos que encontramos según el grado de protección de cada área, dotando a los que presentan un mayor grado de naturalidad de los mayores niveles de protección. En este sentido, a nuestro entender, los cambios en los aprovechamientos (por sus impactos, intensidad de los nuevos usos, alteraciones la topografía, vegetación, etc.) pueden ser determinantes en la evolución de la conservación y, por tanto, del paisaje del área protegida, circunstancias que inciden de lleno sobre los propios motivos que hicieron en su día merecedor al espacio de su distinción como área protegida.

4.- Para finalizar, por el bien de los espacios protegidos, el territorio en general y la calidad de vida en última instancia, entendemos necesario realizar una última apreciación sobre la imperiosa necesidad de coordinar, por un lado, las políticas de protección ambiental y ordenación del territorio (a escala local, subregional y autonómica) y, por otro, las iniciativas regionales, nacionales e internacionales centradas exclusivamente en la protección de la naturaleza. De este modo se evitaría una superposición desorganizada de planteamientos de ordenación y gestión, con consecuencias que afectan a la propia funcionalidad del espacio protegido, su deterioro y las dinámicas territoriales, además de inculcar desconfianza y desinterés por la conservación de los recursos naturales en las poblaciones locales.

\section{Bibliografía}

ARENAS CABELLO, J. M. (1998): «La política de espacios protegidos», en Boletín de la AGE, $\mathrm{n}^{\circ}$ 26, pp. 177-189.

BOSQUE MAUREL, J. (1996): «En torno a los espacios naturales protegidos», en Boletín de la Real Sociedad Geográfica, Tomo CXXXII. Real Sociedad Geográfica. Madrid, pp. 7-20. 
CASTRO NOGUEIRA, H. (2002): Integración territorial de espacios naturales protegidos y conectividad ecológica en paisajes mediterráneos. Consejería de Medio Ambiente (Junta de Andalucía). Sevilla, $124 \mathrm{pp}$.

CONSEJERÍA DE MEDIO AMBIENTE (2004): Usos y coberturas vegetales del suelo de Andalucía: cartografía y estadísticas 1991-1999. Consejería de Medio Ambiente (Junta de Andalucía). Sevilla,

CRUZ VILLALÓN, J. (1999): «La política de ordenación del territorio de Andalucía», en Boletín Económico de Andalucía, no 25, pp. 293-304.

DE ROJAS MARTÍNEZ-PARETS, F. (2006): Los espacios naturales protegidos. Thomson-Aranzadi. Cizur Menor (Navarra), 434 pp.

EUROPARC-ESPAÑA (2002): Plan de Acción para los espacios naturales protegidos del Estado español. Fund. Fernando González Bernáldez. Madrid, 165 pp.

EUROPARC-ESPAÑA (2003): Actas del $9^{\circ}$ Congreso EUROPARC-España. Red Natura 2000: la integración de redes de conservación. Fund. Fernando González Bernáldez. Madrid, 91 pp.

EUROPARC-ESPAÑA (2005): Integración de los espacios naturales protegidos en la ordenación del territorio. Serie Monografías del Plan de Acción, nº 1. Fund. Fernando González Bernáldez. Madrid, $118 \mathrm{pp}$.

EUROPARC-ESPAÑA(2006): Anuario EUROPARC-España del estado de los espacios naturales protegidos 2005. Fund. Fernando González Bernáldez. Madrid, 160 pp.

FUNDICOT (1995): Espacios Naturales Protegidos: Conclusiones. FUNDICOT (http://www.fundicot. org/Documentos/espaciosnat.pdf). Madrid.

GARAYO URRUELA, J. M. (1996): «Concepción integrada de la conservación de la naturaleza y categorías de espacios naturales protegidos», en Lurralde: investigación y espacio, $\mathrm{n}^{\circ} 19$, pp. 215-234.

GARCÍA FERNÁNDEZ-VELILLA, S. (2003): «Conectividad en sistemas regionales de áreas protegidas». En: García Mora, M. R. (Coord.): Conectividad ambiental: las áreas protegidas en la cuenca mediterránea. Consejería de Medio Ambiente (Junta de Andalucía). Sevilla, pp. 89-110.

GARCÍA MORA, M. R. y MONTES, C. (Eds.) (2003): Vínculos en el paisaje mediterráneo. El papel de los espacios protegidos en el contexto territorial. Consejería de Medio Ambiente (Junta de Andalucía). Sevilla, $216 \mathrm{pp}$.

GARZÓN GARCÍA, R. (2004): «Consideraciones sobre el proceso de renovación de los instrumentos de planificación básica de los Parques Naturales andaluces», en Boletín EUROPARC, 18, pp. 41-43.

GÓMEZ MENDOZA, J. (1995): «Desarrollo rural y espacios naturales protegidos». En: Ramos, E. y Cruz, J. (Coords.): Hacia un nuevo sistema rural. MAPA. Madrid, pp. 381-410.

MINISTERIO DE MEDIO AMBIENTE (2005): Perfil ambiental de España 2004: informe basado en indicadores. Ministerio de Medio Ambiente. Madrid, 239 pp.

MOLINA VÁZQUEZ, F. (1986): «La ordenación de los recursos naturales como base indispensable de la gestión de los Parques Naturales». Actas del I Congreso Nacional de Parques Naturales. Agencia de Medio Ambiente (Junta de Andalucía). Sevilla, 176 pp.

MOREIRA MADUEÑO, J. M. (2003): «Las grandes unidades del relieve andaluz», en López Ontiveros, A. (Coord..): Geografía de Andalucía. Ariel. Barcelona, pp. 81-117.

MULERO MENDIGORRI, A. (1999): Introducción al medio ambiente en España. Ariel. Barcelona, $254 \mathrm{p}$.

MULERO MENDIGORRI, A. (2001): «Los espacios naturales protegidos en Andalucía: evolución, caracterización geográfica y singularidades», en Ería, Departamento de Geografía, Universidad de Oviedo, $\mathrm{n}^{\circ}$ 54-55, pp. 141-158.

MULERO MENDIGORRI, A. (2002): La protección de espacios naturales en España: antecedentes, contrastes territoriales, conflictos y perspectivas. Mundi-Prensa. Madrid, $309 \mathrm{pp}$.

MULERO MENDIGORRI, A. (2003): «Los espacios protegidos en Andalucía», en López Ontiveros, A. (Coord..): Geografía de Andalucía. Ariel. Barcelona, pp. 274-292.

TROITIÑO, M. A., MARCOS, F. J., GARCÍA, M., DEL RÍO, M. I., DE LA CALLE, M. y ABAD, L. D. (2005): «Los espacios protegidos en España: significación e incidencia socioterritorial», en Boletín de la AGE, n 39, pp. 227-265. 
VV.AA. (2007): El paisaje mediterráneo, opciones de multifuncionalidad. Cuadernos de Sostenibilidad y patrimonio natural, 11. Fund. Santander Central Hispano. 158 pp.

ZOIDO NARANJO, F. (2002): «Andalucía: cohesión y diversidad territorial», en Scripta Nova. Universidad de Barcelona. Barcelona. 